\title{
Morphogenetic, Ontogenetic and Diurnal Variability in Antimicrobial Activity of Bitter Fennel (Foeniculum vulgare Miller var. vulgare) Essential Oil
}

\author{
Muhammed Akif Açıkgöz ${ }^{1}$, Şevket Metin Kara1", Cansu Aruç², Ebru Ay ${ }^{3}$ \\ ${ }^{1}$ Ordu University, Faculty of Agriculture, Department of Field Crops, 52200-Ordu, TURKEY \\ ${ }^{2}$ Muğla Sıtkı Koçman University, Faculty of Science, Department of Biology, 48000-Muğla, TURKEY \\ ${ }^{3}$ Amasya University, Suluova Vocational School Medicinal and Aromatic Plants Program, 05500-Amasya, TURKEY
}

\begin{abstract}
Background: There has been considerable interest in antimicrobial activity of plant essential oils in recent years. Objectives: This research was carried out to determine morphogenetic, ontogenetic and diurnal variability in antimicrobial activity of bitter fennel essential oil. Methods: To specify morphogenetic variability, leaf and root-bulb-stalk samples taken at pre-, full and post-flowering, flower samples picked at full flowering and seed samples gathered at two seed growth stages were used. For ontogenetic and diurnal variability, whole plant samples were taken at pre-, full and post-flowering and at 9:00 am, 1:00 pm and 5:00 pm. A total of 10 microorganisms have been used to determine antimicrobial activity of essential oils with disc-diffusion and microdilution broth methods. Results: The highest inhibitory effect among leaf essential oils was observed from post-flowering samples, but essential oils of root-bulb-stalk samples of pre-flowering produced the highest antimicrobial activity. Whole plant essential oils of post-flowering samples produced higher antimicrobial activity than those of pre- and full flowering samples. Generally, inhibitory effect of seed essential oils extracted at the beginning of seed formation was higher than those of seed maturity. Daily harvesting time caused no effect on antimicrobial activity of essential oils of whole plant samples. Conclusion: The present study reveals that antimicrobial activity of bitter fennel essential oil significantly vary based on plant parts and growth stages.
\end{abstract}

Keywords: Antibacterial, Antifungal, Growth inhibition, Minimal inhibition concentration, Volatile oil.

\section{INTRODUCTION}

Usage value and economic importance of medicinal and aromatic plants is largely determined by secondary metabolites synthesized in these plants. These naturally occurring bioactive compounds elicit a large scale of antimicrobial and antioxidant activity in man and animals. Among those chemicals essential oils (also known volatile oils), responsible for characteristic aroma or odor of the flower, are of considerable importance. Essential oils, found in a wide range (0.001-25.0\%) in plants, show periodical (pre-, full- and post flowering) and diurnal variability. For example in oil rose, essential oil content reached up its highest value during morning hours and then gradually decreased towards evening, but whereas in some basil species the highest volatile oil content obtained from plants harvested at noon. ${ }^{1,2}$ A study in thyme revealed that the highest volatile oil was produced at flowering stage. ${ }^{3}$

The amount and constituent of volatile oil in different plant parts may also show a large variation. As compared to other plant parts, essential oils are higher in leaves of mint, basil and laurel; in seeds of cumin and coriander; in flowers of oil rose, lavender and violet and in roots of cinnamon. In fennel
DOI: $10.5530 /$ ijper.51.3s.10 Correspondence: Sevket Metin Kara, Ordu University, Faculty of Agriculture, Department of Field Crops, 52200-Ordu, TURKEY

Contact: (+90) 5327938115 E-mail: smkara58@hotmail. com

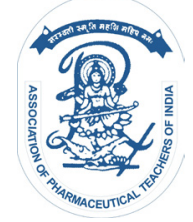

www.ijper.org 
species, a member of the family Apiaceae typical of the Mediterranean region, volatile oils are accumulated in root-bulb-stalk, leaf, flower and seed. ${ }^{4-6}$ In the literature, there was no study aimed at determining variability in antimicrobial activity of Foeniculum vulgare Miller var. vulgare volatile oil. Therefore, the present study was carried out to determine morphogenetic, ontogenetic and diurnal variability in antimicrobial activity of bitter fennel essential oil.

\section{MATERIAL AND METHOD}

The field part of the study was carried out in 2012 and 2013 years, with a total of 500 fennel plants grown using standard production practices. To specify morphogenetic variability; leaf and root-bulb-stalk samples were taken at three plant growth stages (pre-, full- and post-flowering), flower samples were picked up at full flowering and seed samples were gathered at two seed growth stages (at the beginning of seed formation and seed maturity). Whole plant samples were used to clarify ontogenetic (pre-, full and post-flowering) and diurnal (harvesting at 9:00 am, 1:00 pm and 5:00 pm) variability. A total of 20 plants were used in each sampling.

Volatile oils of the plant samples were extracted using hydro-distillation method with standard Clevenger apparatus. Antimicrobial activity of volatile oils were assessed against 10 microorganisms, including 7 bacteria and 3 fungi. Disc Diffusion (DD) method was employed to determine antimicrobial activities of essential oils. ${ }^{7}$ In determining Minimum Inhibition Concentration (MIC), in accordance with CLSI recommendations, a microdilution broth susceptibility assay was used. ${ }^{7}$ Test strains were suspended in $\mathrm{MHB}$ and $\mathrm{SDB}$ to give a final density of $5 \times 10^{5} \mathrm{CFU} / \mathrm{ml}$ and these were confirmed by viable counts. A series of dilutions were prepared in the range $0.072-72.0 \mathrm{mg} / \mathrm{ml}$ of the essential oil in a 96-well microtitre plate, including growth control (MHB/SDB+Tween 80) and sterility control (MHB/ SDB+Tween $80+$ test oil). Antibiotics were used as a reference compound for antibacterial and antifungal activities. All tests were made in triplicate.

\section{RESULTS AND DISCUSSION}

The values given here were the means of the two study years, as no significant differences observed among antimicrobial activities of essential oils of fennel plants grown in 2012 and 2013 years. All essential oils extracted from various plant parts (root-bulb-stalk, leaf, flower and seed), sampled at different growth stages and daily hours, showed antimicrobial activity against 8 microorganisms, out of 10 used in the study. No antimicrobial activity of any volatile oils, however, was detected against microorganisms of S.cerevisiae and A.niger.

The essential oils extracted from the seed samples gathered at the beginning of seed formation showed the highest antimicrobial activity obtained in the study, giving the largest zone diameters of 12-17 $\mathrm{mm}$ (Table 1). As the seeds matured, zone diameters became smaller $(8-12 \mathrm{~mm})$ and antimicrobial activity decreased. Similarly, the seed samples at the beginning of seed formation showed MIC values of $2.25-36 \mu \mathrm{g} / \mathrm{ml}$, but with seed maturity MIC values increased to $9-72 \mu \mathrm{g} / \mathrm{ml}$. The volatile oils of the flower samples had the second highest zone diameters $(12-14 \mathrm{~mm})$ and the second lowest MIC (4.50-36 $\mu \mathrm{g} / \mathrm{ml})$ values, indicating a good level of antimicrobial activity.

Among the leaf samples taken at three growth stages, those of post-flowering produced the highest antimicrobial activity with zone diameters of 11-14 $\mathrm{mm}$ and MIC values of 4.50-18 $\mu \mathrm{g} / \mathrm{ml}$ (Table 1). In general, zone diameters were smaller in leaf samples of pre-flowering $(9-12 \mathrm{~mm})$ and full-flowering $(8-13 \mathrm{~mm})$, as compared to post-flowering samples. In contrast to the leaf samples, the highest antimicrobial activity of volatile oils of rootbulb-stalk was obtained from the samples taken preflowering with zone diameters of $10-11 \mathrm{~mm}$. At full- and post-flowering periods, zone diameters were generally lower with $7-9 \mathrm{~mm}$ in full-flowering and $5-8 \mathrm{~mm}$ in postflowering. The MIC values of root-bulb-stalk samples taken at three stages, however, were almost similar to each other and showed a variation from 18 to $72 \mu \mathrm{g} / \mathrm{ml}$. In terms of ontogenetic variability, inhibition zone varied in the ranges of $9-13 \mathrm{~mm}$ in pre-flowering stage, $8-13 \mathrm{~mm}$ in full-flowering and $10-14 \mathrm{~mm}$ in post-flowering stages, a slight increase in antimicrobial activity in post-flowering samples (Table 2). On the other hand, the MIC values of the whole plan samples taken at post-flowering were remarkably smaller (higher antimicrobial activity) than those of pre- and full-flowering samples.

In general, daily variation of harvesting time (that is; diurnal variability) did not produce any significant effects on zone diameters and MIC values obtained with the essential oils of the whole plant samples (Table 3). However, variations arising from plant growth stages (pre-, full- and post flowering) affected microbial activity and MIC values of essential oils. The essential oils of post-flowering samples generally produced higher antimicrobial activity and lower MIC value, as compared to volatile oils of pre- and full-flowering samples.

A high level of antimicrobial activity of essential oils extracted from fennel species against several microorganisms has already been proved by a number of previous studies. ${ }^{8-13}$ On the other hand, there have been some 
Table 1: Antimicrobial activity of bitter fennel essential oils extracted from flowers at full-flowering, seeds harvested at the beginning of seed formation and maturity, leaves and root-bulb-stalk samples taken at pre-full and post-flowering.

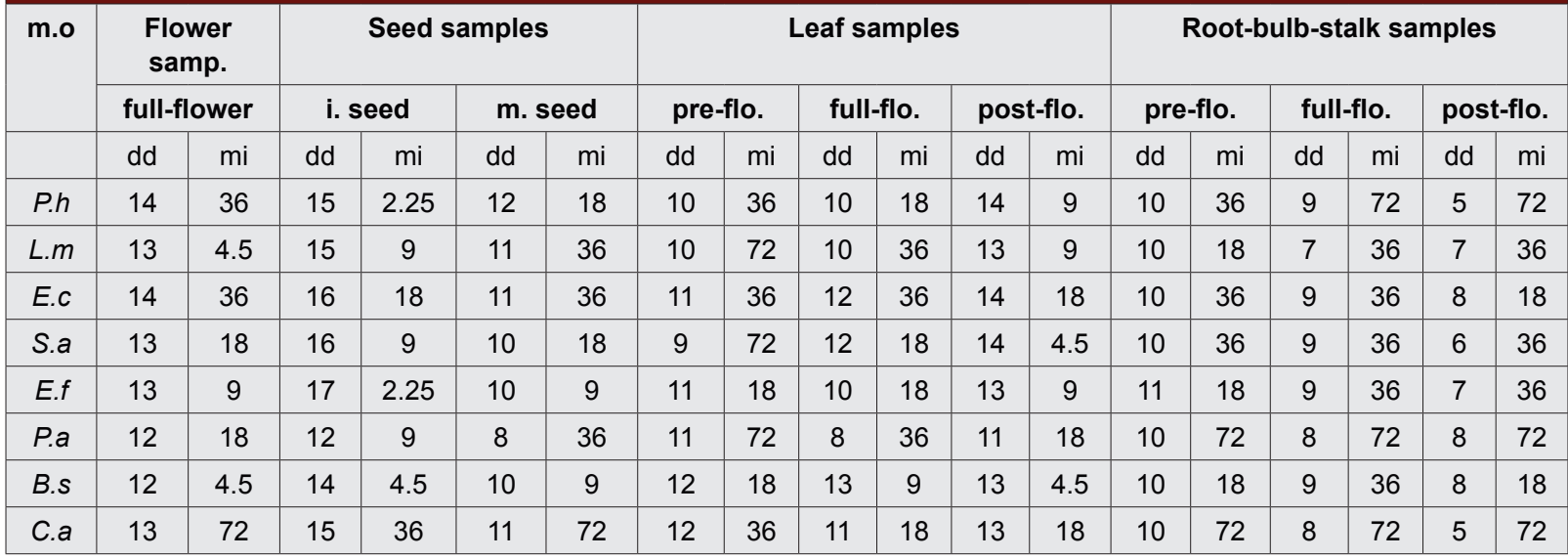

${ }^{a}$ flo, flowering; ${ }^{b} \mathrm{~m}$, mature; $\mathrm{c}_{\text {, immature; }}{ }^{\mathrm{d}} \mathrm{dd}$, disc diffusion method. Diameter of inhibition zone (mm) including disc diameter of 6 mm; ${ }^{\mathrm{e}} \mathrm{mi}$, minimum inbitory concentration. Values given for the bitter fennel essantial oil as $\mathrm{mg} / \mathrm{ml}$, for antibiotics as $\mu \mathrm{g} / \mathrm{ml} ;{ }^{f} \mathrm{~m} .0$, microorganisms; ${ }^{1}$ P.h, Proteus hauseri ATCC ${ }^{13315}$; ${ }^{2}$ L.m, Listeria monocytogenes ATCC 7644; ${ }^{3}$ E.C, Escherichia coli ATCC $25922 ;{ }^{4}$ S.a, Staphylococcus aureus ATCC 6538P; ${ }^{5}$ E.f, Enterococcus faecalis DC $74 ;{ }^{6}$ P.a Pseudomonas auroginosa ATCC $9027 i^{7}$ B.s, Baciilus subtilis ATCC $6633 i^{8}$ C.a, Candida albicans ATCC 10239.

\begin{tabular}{|c|c|c|c|c|c|c|c|c|c|c|c|c|c|c|c|c|}
\hline \multirow{3}{*}{ m.o } & \multicolumn{6}{|c|}{ whole plant harvesting stages } & \multicolumn{10}{|c|}{ tested antibiotics } \\
\hline & \multicolumn{2}{|c|}{ pre-flo. } & \multicolumn{2}{|c|}{ full-flo. } & \multicolumn{2}{|c|}{ post-flo. } & \multicolumn{2}{|c|}{ penicillin } & \multicolumn{2}{|c|}{ ampicillin } & \multicolumn{2}{|c|}{ gentamicin } & \multicolumn{2}{|c|}{ vankomycin } & \multicolumn{2}{|c|}{ nystatin } \\
\hline & dd & $\mathrm{mi}$ & $\mathrm{dd}$ & $\mathrm{mi}$ & $\mathrm{dd}$ & mi & $\mathrm{dd}$ & mi & $\mathrm{dd}$ & mi & dd & mi & dd & mi & $\mathrm{dd}$ & $\mathrm{mi}$ \\
\hline P.h & 10 & 9 & 8 & 18 & 10 & 4.5 & 17 & nt & na & 0.25 & na & 0.13 & na & 128 & nt & nt \\
\hline L.m & 9 & 72 & 9 & 36 & 11 & 4.5 & 20 & 8 & 10 & 8 & na & 0.5 & 25 & nt & nt & nt \\
\hline E.c & 13 & 36 & 11 & 36 & 13 & 4.5 & 12 & 32 & 10 & 16 & 20 & nt & na & nt & nt & nt \\
\hline S.a & 9 & 72 & 11 & 72 & 11 & 36 & 35 & 128 & 45 & nt & na & nt & 15 & 1 & $\mathrm{nt}$ & nt \\
\hline E.f & 10 & 18 & 9 & 9 & 12 & 9 & 17 & 2 & 25 & nt & na & nt & 17 & 4 & nt & nt \\
\hline P.a & 10 & 72 & 8 & 36 & 10 & 9 & 13 & 128 & na & nt & na & nt & na & nt & nt & nt \\
\hline B.s & 10 & 18 & 13 & 18 & 13 & 9 & 30 & $\mathrm{nt}$ & 25 & $\mathrm{nt}$ & na & 4 & 25 & 4 & $\mathrm{nt}$ & $\mathrm{nt}$ \\
\hline C.a & 10 & 72 & 8 & 72 & 14 & 36 & $\mathrm{nt}$ & nt & $\mathrm{nt}$ & nt & nt & nt & nt & $\mathrm{nt}$ & 25 & 128 \\
\hline
\end{tabular}

${ }^{a}$ na, not active; ${ }^{b}$ t, not tested.

\begin{tabular}{|c|c|c|c|c|c|c|c|c|c|c|c|c|c|c|c|c|c|c|}
\hline \multirow[t]{3}{*}{ m.o } & \multicolumn{6}{|c|}{ harvesting at 9:00am } & \multicolumn{6}{|c|}{ harvesting at $1: 00 \mathrm{pm}$} & \multicolumn{6}{|c|}{ harvesting at 5:00pm } \\
\hline & \multicolumn{2}{|c|}{ pre-flo. } & \multicolumn{2}{|c|}{ full-flo. } & \multicolumn{2}{|c|}{ post-flo. } & \multicolumn{2}{|c|}{ pre-flo. } & \multicolumn{2}{|c|}{ full-flo. } & \multicolumn{2}{|c|}{ post-flo. } & \multicolumn{2}{|c|}{ pre-flo. } & \multicolumn{2}{|c|}{ full-flo. } & \multicolumn{2}{|c|}{ post-flo. } \\
\hline & dd & $\mathrm{mi}$ & dd & $\mathrm{mi}$ & dd & mi & dd & $\mathrm{mi}$ & dd & $\mathrm{mi}$ & dd & $\mathrm{mi}$ & dd & $\mathrm{mi}$ & dd & mi & dd & $\mathrm{mi}$ \\
\hline P.h & 8 & 9 & 9 & 18 & 11 & 4.5 & 9 & 9 & 10 & 18 & 11 & 4.5 & 9 & 9 & 10 & 18 & 11 & 4.5 \\
\hline L. $m$ & 7 & 72 & 8 & 36 & 9 & 4.5 & 8 & 72 & 9 & 36 & 9 & 4.5 & 7 & 72 & 9 & 36 & 9 & 4.5 \\
\hline E.c & 7 & 36 & 9 & 36 & 12 & 4.5 & 7 & 36 & 9 & 36 & 12 & 4.5 & 7 & 36 & 9 & 36 & 12 & 4.5 \\
\hline S.a & 8 & 72 & 10 & 72 & 11 & 36 & 8 & 72 & 11 & 72 & 11 & 36 & 8 & 72 & 10 & 72 & 11 & 36 \\
\hline E.f & 7 & 18 & 8 & 9 & 10 & 9 & 7 & 18 & 8 & 9 & 10 & 9 & 7 & 18 & 8 & 9 & 10 & 9 \\
\hline P.a & 9 & 72 & 8 & 36 & 9 & 9 & 9 & 72 & 8 & 36 & 9 & 9 & 8 & 72 & 8 & 36 & 9 & 9 \\
\hline B.s & 9 & 18 & 11 & 18 & 11 & 9 & 9 & 18 & 10 & 18 & 11 & 9 & 9 & 18 & 11 & 18 & 11 & 9 \\
\hline C.a & 10 & 72 & 11 & 72 & 10 & 36 & 10 & 72 & 11 & 72 & 10 & 36 & 9 & 72 & 11 & 72 & 10 & 36 \\
\hline P.h & na & $\mathrm{nt}$ & na & $\mathrm{nt}$ & na & $\mathrm{nt}$ & na & nt & na & $\mathrm{nt}$ & na & $\mathrm{nt}$ & na & $\mathrm{nt}$ & na & $\mathrm{nt}$ & na & $\mathrm{nt}$ \\
\hline L.m & na & $\mathrm{nt}$ & na & nt & na & nt & na & $\mathrm{nt}$ & na & $\mathrm{nt}$ & na & $\mathrm{nt}$ & na & nt & na & $\mathrm{nt}$ & na & nt \\
\hline
\end{tabular}


studies indicating that fennel seeds had a good level of antibacterial and antifungal activity. ${ }^{14-15}$

\section{CONCLUSION}

This study revealed that, similar to most of the previous studies, volatile oils of seeds produced the highest antimicrobial activity in bitter fennel (Foeniculum vulgare Miller var. vulgare), as compared to other plant parts. As the seeds matured, however, zone diameters became smaller and antimicrobial activity decreased. No antimicrobial effect of any volatile oils was detected against microorganisms of $S$. cerevisiae and $A$. niger. The essential oils of post-flowering samples generally produced higher antimicrobial activity as compared to those of pre- and full-flowering samples. Furthermore, the effect of diurnal variability in bitter fennel volatile oils on microbial activity was found to be non-significant.

\section{ACKNOWLEDGEMENT}

Authors are highly thankful to Scientific Research Projects Unit (BAP) of Ordu University for providing support to this research, as a part of AR-1317 BAP project

\section{CONFLICT OF INTEREST}

None

\section{ABBREVIATIONS}

CLSI: Clinical and Laboratory Standards Institute; MHB: Mueller hinton agar; SDB: Sabouraud dextrose agar; MIC: Minimum Inhibition Concentration; DD: Disc Diffusion; CFU: Colony-forming unit; flo: flowering; m: mature; i: immature; m.o: microorganisms; P.h: Proteus hauseri ATCC 13315; L.m: Listeria monocytogenes ATCC 7644; E.c: Escherichia coli ATCC 25922; S.a: Staphylococcus aureus ATCC 6538P; E.f: Enterococcus faecalis DC 74; P.a: Pseudomonas auroginosa ATCC 9027; B.s: Baciilus subtilis ATCC 6633; C.a: Candida albicans ATCC 10239; na: not active; nt: not tested.

\section{REFERENCES}

1. Kumar R, Sharma S, Sood S, Agnihotri VK, Singh B. Effect of diurnal variability and storage conditions on essential oil content and quality of damask rose (Rosa damascena Mill.) flowers in north western Himalayas. Scientia Horticulturae 2013;154:102-8.

2. Padalia RC, Verma RS, Chauhan A. Diurnal variations in aroma profile of Ocimum basilicum L., O. gratissimum L., O. americanum L., and O. kilimandscharicum Guerke. Journal of Essential Oil Research. 2016;19(6):1442-53

3. Ebrahimi SN, Hadian J, Mirjalili MH, Sonboli A, Yousefzadi M. Essential oil composition and antibacterial activity of Thymus caramanicus at different phonological stages. Food chemistry. 2008;110(4):927-31.

4. Özcan MM, Chalchat JC, Arslan D, Ateş A, Ünver A. Comparative essential oil composition and antifungal effect of bitter fennel (Foeniculum vulgare ssp. piperitum) fruit oils obtained during different vegetation. Journal of medicinal food. 2006;9(4):552-61.

5. Telci I, Demirtas I, Sahin A. Variation in plant properties and essential oil composition of sweet fennel (Foeniculum vulgare Mill.) fruits during stages of maturity. Industrial Crops and Products 2009;30(1):126-30.

6. Diao WR, Hu QP, Zhang H, Xu JG. Chemical composition, antibacterial activity and mechanism of action of essential oil from seeds of fennel (Foeniculum vulgare Mill.). Food Control 2014;35(1):109-16.

7. Wayne PA. Performance standards for antimicrobial disk susceptibility tests; approved standard. Clinical and Laboratory Standards Institute (CLSI) document, Eleventh Edition. 2012;M02-A11.

8. Soylu S, Yigitbas H, Soylu EM, Kurt Ş. Antifungal effects of essential oils from oregano and fennel on Sclerotinia sclerotiorum. Journal of Applied Microbiology 2007;103(4):1021-30.

9. Reichling J, Schnitzler P, Suschke U, Saller R. Essential oils of aromatic plants with antibacterial, antifungal, antiviral, and cytotoxic properties-an overview. Research in Complementary Medicine. 2009;16(2):79-90.

10. Miguel MG, Cruz C, Faleiro L, Simoes MT, Figueiredo AC, Barroso JG, et al. Foeniculum vulgare essential oils: chemical composition, antioxidant and antimicrobial activities. Natural product communications. 2010;5(2):319-28.

11. Shahat AA, Ibrahim AY, Hendawy SF, Omer EA, Hammouda FM, Abdel-Rahman $\mathrm{FH}$, et al. Chemical composition, antimicrobial and antioxidant activities of essential oils from organically cultivated fennel cultivars. Molecules. 2011;16(2):1366-77.

12. Roby MHH, Sarhan MA, Selim KAH, Khalel KI. Antioxidant and antimicrobial activities of essential oil and extracts of fennel (Foeniculum vulgare L.) and chamomile (Matricaria chamomilla L). Industrial crops and products. 2013;44:437-45.

13. Senatore F, Oliviero F, Scandolera E, Taglialatela-Scafati O, Roscigno G, Zaccardelli $\mathrm{M}$, et al. Chemical composition, antimicrobial and antioxidant activities of anethole-rich oil from leaves of selected varieties of fennel [Foeniculum vulgare Mill. ssp. vulgare var. azoricum (Mill.) Thell]. Fitoterapia. 2013;90:214-9.

14. Lo Cantore P, lacobellis NS, De Marco A, Capasso F, Senatore F. Antibacterial activity of Coriandrum sativum $\mathrm{L}$. and Foeniculum vulgare Miller var. vulgare (Miller) essential oils. Journal of agricultural and food chemistry 2004; 52(26):7862-7866.

15. Anwar F, Ali M, Hussain Al, Shahid M. Antioxidant and antimicrobial activities of essential oil and extracts of fennel (Foeniculum vulgare Mill.) seeds from Pakistan. Flavour and Fragrance Journal 2009; 24(4):170-176. 


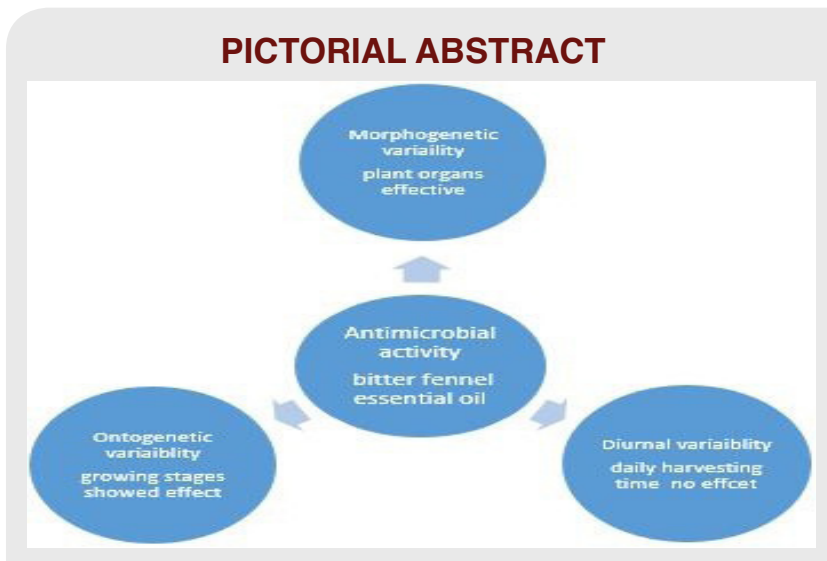

\section{About Authors}

- Plant essential oils are of considerable importance as antimicrobial agents.

- Antimicrobial activity of essential oils may greatly wary depending on plant organs, growing stages and daily harvesting hours.

- Variability in microbial activity of bitter fennel essential oils was investigated against different microbial strains and results were statistically interpreted.

- Daily harvesting time caused no effect on antimicrobial activity of essential oils fennel plants.

- Antimicrobial activity of bitter of fennel essential oil significantly vary based on plant parts and growth stages.

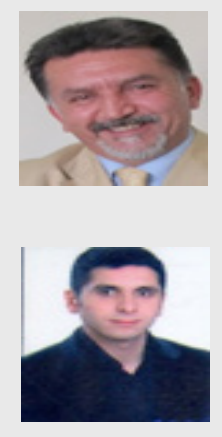

Prof. Dr. Sevket Metin Kara: He is the professor of department of Field Crops of Agricultural Faculty, Ordu University. His area of research is oil crops and medicinal and aromatic plants. He has more than 20 years of teaching and research experience in Field Crops.

Muhammed Akif Açıgöz: He is currently a PhD student at Field Crops Department in Ordu University of Turkey. His research areas include tissue culture, volatile oils and secondary metabolites in medicinal and aromatic plants.

Cite this article: Açikgöz MA, Kara SM, Aruç C, Ay E. Morphogenetic, Ontogenetic and Diurnal Variability in Antimicrobial Activity of Bitter Fennel (Foeniculum vulgare Miller var. vulgare) Essential Oil. Indian J of Pharmaceutical Education and Research. 2017;51(3)Suppl:S190-94. 